\title{
Quantitative Determination of Deltamethrin in Milk, Blood and Urine of Domestic Animals
}

\author{
Zulfiqar Ali, Rubina Gilani, Habib Hussain, Imdad Hussain \\ Department of Chemistry, University of Engineering and Technology, Lahore- Pakistan
}

\begin{abstract}
Deltamethrin among pyrethroids is used as an insecticide on different vegetables. Grass of sprayed field was provided to the domestic animals as a food. In order to determine deltamethrin quantitatively, animal samples like milk, blood and urine were extracted with n-hexane, partitioned and anhydrous $\mathrm{Na}_{2} \mathrm{SO}_{4}$ was added to the acetonitrile layer to remove the water contents. Silica gel column was used to cleanup deltamethrin with $n$-hexane and diethyl ether as a mobile phase. The column fractions were concentrated to $5 \mathrm{ml}$ using rotary evaporator and analyzed using Gas Chromatography with Flame Ionization Detector (GC-FID).Deltamethrin solutions with concentrations ranging from $0.5-t o 2.5-\mu \mathrm{g} / \mathrm{ml}$ were used as calibration standards. The solution at $1.0 \mu \mathrm{g} / \mathrm{ml}$ is used to confirm the claimed limit of detection (LOD).
\end{abstract}

Keywords: Deltamethrin, Milk, Blood, Urine, Vegetables

\section{Introduction}

Pyrethroids are a group of man-made pesticides similar to the natural pesticide pyrethrum which is produced by chrysanthemum flowers. Pyrethroids now constitute the majority of commercial household insecticides [1]. Although more than 1000 pyrethroids have been made Pyrethroids are found in many commercial products used to control insects, including household insecticides, pet sprays and shampoos.

Some pyrethroids are used as lice treatments applied directly to the head and as mosquito repellents that can be applied to clothes. Pyrethroids are lethal to mayflies, gadflies and invertebrates that constitute the base of many aquatic and terrestrial food webs [2]. Some common examples of pyrethroid insecticides are deltamethrin and permethrin.

Deltamethrin was synthesized in 1974 and first marketed in 1977. Deltamethrin products are among some of the most popular and widely used insecticides in the world. Since this material is considered to be a safe insecticide that's why it is being sold in many countries for agriculture, public health and live stock applications [3,4]. Deltamethrin is rapidly paralyzing the insect nervous system giving a quick knockdown effect [5].

Deltamethrin is widely sprayed on leafy vegetable like lettuce, lady's finger and spinach to kill the insecticides. Over $98 \%$ of sprayed insecticides and $95 \%$ of herbicides reach a destination other than their target species, including non-target species, air, water and soil [6]. In humans, it was observed that deltamethrin can pass from a woman's skin through her blood and into her breast milk [7]. In addition, it was analysed that deltamethrin is absorbed in the vegetables and is found to be $0.2-\mathrm{mg} / \mathrm{kg}$ of the vegetable [8]. In Canada, 126 samples of vegetables and 2 samples of fruits were extracted and analyzed for insecticide residues by procedures adapted from methods available in the literature [9]. In the samples, the residual pesticide was found but less than the maximum residue limit (MRL). Moreover deltamethrin is quantitatively analyzed with high performance liquid chromatography [10].

In Pakistan, deltamethrin is one of the most extensively used pesticides on different vegetables especially on Lady's finger. Farmers used these pesticides in excess without considering their recommended limits. Grass of sprayed field was being provided as a food to animals like buffalos $250 \mathrm{~kg}$ average weight. In this agricultural area of Pakistan (Hydyara Lahore) some diseases were found to be very common in humans especially in children like paresthesia, salivation, nausea and vomiting and reddening of skin in men working in the feild. Since metabolism in humans may be similar to that in animals so it was therefore, decided to analyze the animal samples because humans are directly or indirectly linked with animals. The residual quantity of deltamethrin in animal samples like milk, blood and urine were estimated by GC-FID and were compared with Maximum Residue Limit (MRL) values set by Environmental Protection Agency (EPA).

\section{Chemicals and Standards}

Solvents and reagents used for pesticide residual analysis were Merck products of analytical grade: Acetonitrile, n-hexane, zinc acetate and $\mathrm{Na}_{2} \mathrm{SO}_{4}$ used without further purification. Analytical standard or pure active ingredients of deltamethrin were obtained from "Ali Akbar Group Pesticide Industry, Lahore-Pakistan. 


\section{Experimental Section}

Deltamethrin was extracted from collected samples through solvent extraction method. Acetone, hexane, methanol, petroleum ether, acetonitrile, dichloromethane and their mixtures [11-15] are reported for satisfactory extractants to study the pyrethroids.

\subsection{Deltamethrin Extraction from Different Samples}

$50 \mathrm{ml}$ milk sample was taken in a conical flask and $8-10$ gm zinc acetate was added in it to remove the fats. Bissacot DZ et al reported the procedure for analysis of milk samples and this procedure was used with slight modification [16]. Milk sample was filtered and filtrate was added in a separating funnel. To extract deltamethrin from this extract, $100 \mathrm{ml}$ of $\mathrm{n}$-hexane was added in a separating funnel. After shaking $\mathrm{n}$-hexane and milk sample for 2-3 minutes, organic layer containing deltamethrin was separated and further $50 \mathrm{ml}$ of $\mathrm{n}$-hexane was added to the aqueous layer to remove the possible traces of pesticide.

The filtrate (organic layers) was transferred to a $250 \mathrm{ml}$ separating funnel and partitioned by $100 \mathrm{ml}$ acetonitrile. The above mixture was shaken for 3-5 minutes and acetonitrile layer was collected separately. 10 gm anhydrous $\mathrm{Na}_{2} \mathrm{SO}_{4}$ was added to the acetonitrile layer to remove the water contents. At the end, silica gel column was used to cleanup deltamethrin with $n$-hexane and diethyl ether as a mobile phase. The deltamethrin fractions were concentrated to $5 \mathrm{ml}$ by using rotary evaporator and analyzed by GC-FID (Gas ChromatographyFlame Ionization Detector).

\subsubsection{Blood}

According to the modified procedure of Bissacot DZ et al [16], $25 \mathrm{ml}$ of the whole blood without separating serum was taken in a separating funnel and deltamethrin was extracted with $50 \mathrm{ml}$ of $\mathrm{n}$-hexane and acetone mixture $(8: 2 \mathrm{v} / \mathrm{v})$. Organic layer containing deltamethrin was separated in another beaker.

$50 \mathrm{ml}$ acetonitrile was added to the filtrate (organic layers) in a $250 \mathrm{ml}$ separating funnel. After shaking above mixture for 3-5 minutes, acetonitrile layer was collected. Water contents were removed from acetonitrile by adding $5 \mathrm{gm}$ anhydrous $\mathrm{Na}_{2} \mathrm{SO}_{4}$. At the end silica gel column is used to cleanup deltamethrin with $n$-hexane and diethyl ether as a mobile phase. The deltamethrin fractions were combined, concentrated to 5 $\mathrm{ml}$ by using rotary evaporator and analyzed by GC-FID.

\subsubsection{Urine}

In order to remove dust and other suspended particles, urine sample was filtered to make it transparent. By following Bissacot DZ et al procedure, $50 \mathrm{ml}$ of urine sample was taken in a separating funnel and deltamethrin was extracted with $100 \mathrm{ml}$ of $\mathrm{n}$-hexane. Organic layer containing deltamethrin was separated and $50 \mathrm{ml}$ of $\mathrm{n}$-hexane was again added to the aqueous layer to remove the possible traces of pesticide.

$100 \mathrm{ml}$ acetonitrile was taken in a $250 \mathrm{ml}$ separating funnel to extract deltamethrin from filtrate. The filtrate was shaken with acetonitrile for 3-5 minutes and organic layer was collected. 10 gm anhydrous $\mathrm{Na}_{2} \mathrm{SO}_{4}$ was added to the acetonitrile layer to remove the water contents. In order to clean up deltamethrin, silica gel column was used with $n$-hexane and diethyl ether as a mobile phase. The fractions obtained from silica gel column were combined and concentrated to $5 \mathrm{ml}$ by using rotary evaporator and analyzed by GC-FID.

\subsection{Equipments and Conditions}

Deltamethrin was extracted from milk, blood and urine samples of domestic animals and analyzed by GC-FID technique. The extracts obtained were subjected to analysis under the following GC conditions. Apparatus, Shimadzu GC 14-A; column, DB-5; column length, 25m; column temperature, $60{ }^{\circ} \mathrm{C}$ (2min) $-8^{\circ} \mathrm{C} / \mathrm{min}-280{ }^{\circ} \mathrm{C}$; inlet tempreture, $240{ }^{\circ} \mathrm{C}$; detector temperature, $280{ }^{\circ} \mathrm{C}$; carrier gas, He; flow rate, 2 $\mathrm{ml} / \mathrm{min}$; detector, FID); injection method, splitless; injection volume, $1 \mu \mathrm{l}$.

\section{Results and Discussion}

Deltamethrin is considered to be safe pesticide and can be used in home as well as on crops.

Deltamethrin is an active ingredient of a common insecticide known as deltaphos. It is a safe pesticide, if its residual limit in any food material or body is less than the Recommended Maximum Residue Limits (MRL) set by EPA.

In order to check the toxicity of deltamethrin, grass was provided as a food to the animals from the sprayed field. Blood, urine and milk samples are taken from the animals according to the recommended methods and analyzed by GC-FID. The structural formula of deltamethrin is given bellow in Figure 1. 
<smiles>CC1(C)C(C=C=C(Br)Br)C1C(=O)OC(C#N)c1cccc(Oc2ccccc2)c1</smiles>

Fig 1 Structure formula of deltamethrin

In order to check the purity of standard deltamethrin, the solutions with concentrations ranging from $0.5-$ to $2.5-\mu \mathrm{g} / \mathrm{ml}$ were used as calibration standards as given in Table 1 . The solution at $1.0 \mu \mathrm{g} / \mathrm{ml}$ was used to confirm the claimed limit of detection (LOD).

Table.1 Calibration of pure deltamethrin

\begin{tabular}{cccc}
\hline S.No. & Conc. & Area under curve & Retention Time \\
\cline { 2 - 4 } & $(\mathrm{ppm})$ & $(\mathrm{mv} / \mathrm{sec})$. & $(\mathrm{min})$ \\
\hline & & & \\
1 & 0.5 & 2655 & 7.021 \\
2 & 1.0 & 5315 & 7.019 \\
3 & 1.5 & 7971 & 7.120 \\
4 & 2.0 & 10629 & 8.015 \\
5 & 2.5 & 12500 & 7.823 \\
\hline
\end{tabular}

Note: Calibration is done by GC-FID under above mentioned conditions. The concentrations, which were used for calibration of standard deltamethrin, are plotted against the area under curves as given in Figure 2.

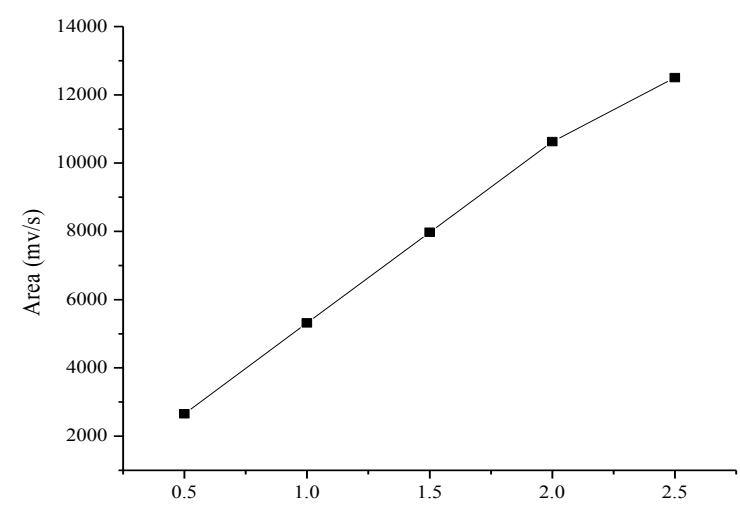

Figure No 2. Graph between concentration and curve area

The linearity in the curve showed that standard deltamethrin is pure and can be used for quantitative determination of deltamethrin in different samples. The quantity of deltamethrin determined in various samples is summarized bellow in Table 2 .

Table 2: The details of deltamethrin samples

\begin{tabular}{|c|c|c|c|c|c|c|c|c|}
\hline \multirow[t]{2}{*}{ Samples } & \multicolumn{4}{|c|}{ Area under curves $(\mathrm{mv} / \mathrm{s})$} & \multirow{2}{*}{$\begin{array}{l}\text { Retention } \\
\text { time (min) }\end{array}$} & \multirow{2}{*}{$\begin{array}{l}\text { Conc. } \\
\text { in } \\
\mathrm{ug} / \mathrm{ml}\end{array}$} & \multirow{2}{*}{$\begin{array}{l}\text { Conc. in } \\
\text { ug/50g }\end{array}$} & \multirow{2}{*}{$\begin{array}{l}\text { Conc. in } \\
\text { ppm. }\end{array}$} \\
\hline & $\begin{array}{c}1 \\
(\mathrm{AUC}) \\
\end{array}$ & $\begin{array}{c}2 \\
(\mathrm{AUC}) \\
\end{array}$ & $\begin{array}{c}3 \\
(\mathrm{AUC}) \\
\end{array}$ & Average & & & & \\
\hline Sample $\mathrm{S}_{1}$ & 3846 & 3846 & 3845 & 3845.66 & 6.920 & 0.709 & 7.090 & 0.1418 \\
\hline Sample $\mathrm{S}_{2}$ & 3842 & 3841 & 3841 & 3841.33 & 6.972 & 0.708 & 3.540 & 0.0708 \\
\hline Sample $\mathrm{S}_{3}$ & Nil & Nil & Nil & $\ldots$ & ... & $\ldots$ & $\ldots$ & $\ldots$ \\
\hline $\begin{array}{l}\text { Standard } \\
\text { (Std.) }\end{array}$ & 5315 & 5314 & 5316 & 5315 & 7.120 & 1.0 & $\ldots$ & $\cdots$ \\
\hline
\end{tabular}

Note: Retention time of each sample is the average of three readings. 
The natures of the samples are given in Table 3 .

Table 3. Samples and their Nature

\begin{tabular}{ccc}
\hline S.No & Samples & Nature of sample \\
\hline 1 & Sample $\mathrm{S}_{1}$ & Blood Sample \\
2 & Sample $\mathrm{S}_{2}$ & Urine Sample \\
3 & Sample $\mathrm{S}_{3}$ & Milk Sample \\
\hline
\end{tabular}

Note: Retention time of each sample is the average of three readings.

The concentration of deltamethrin in blood and urine samples was found to be 0.1418 and 0.0708 $\mathrm{mg} / \mathrm{kg}$ respectively. Literature showed that deltamethrin should present in milk samples but in our samples concentration of deltamethrin was very less and could not be detected. The concentration of deltamethrin in blood and urine samples were compared with the standard maximum residue limits (MRL). MRL values of deltamethrin in blood and urine are $0.05 \mathrm{mg} / \mathrm{kg}$ and $0.02 \mathrm{mg} / \mathrm{kg}$ respectively.

The analyzed concentration of deltamethrin in these samples is very high as compared to the recommended MRL or tolerance limits [17]. Such a high concentration of deltamethrin is very dangerous and toxic to the animals and can produce lot of harmful diseases in them. The scan of deltamethrin standard and sample are given in Figure 3.

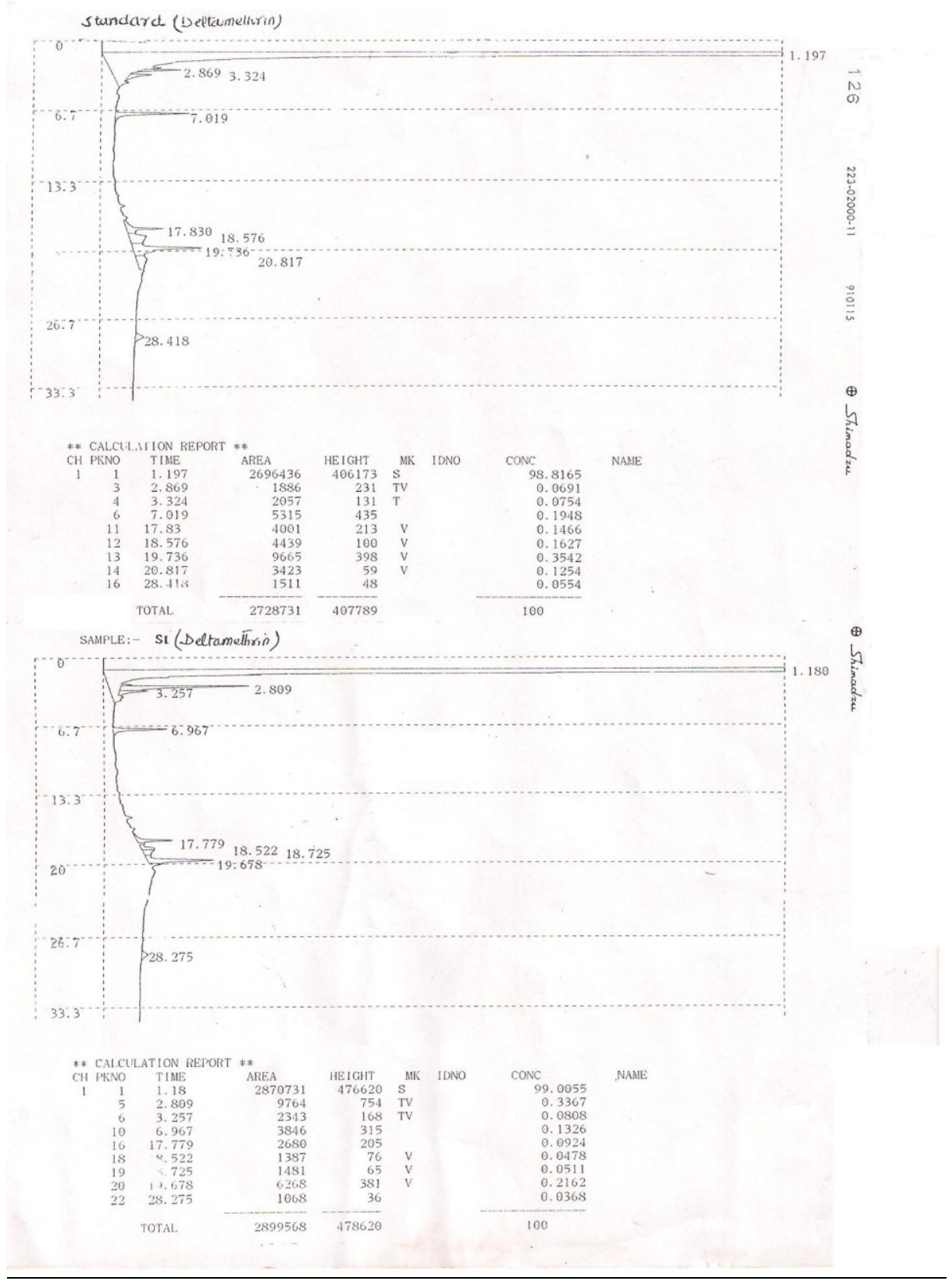




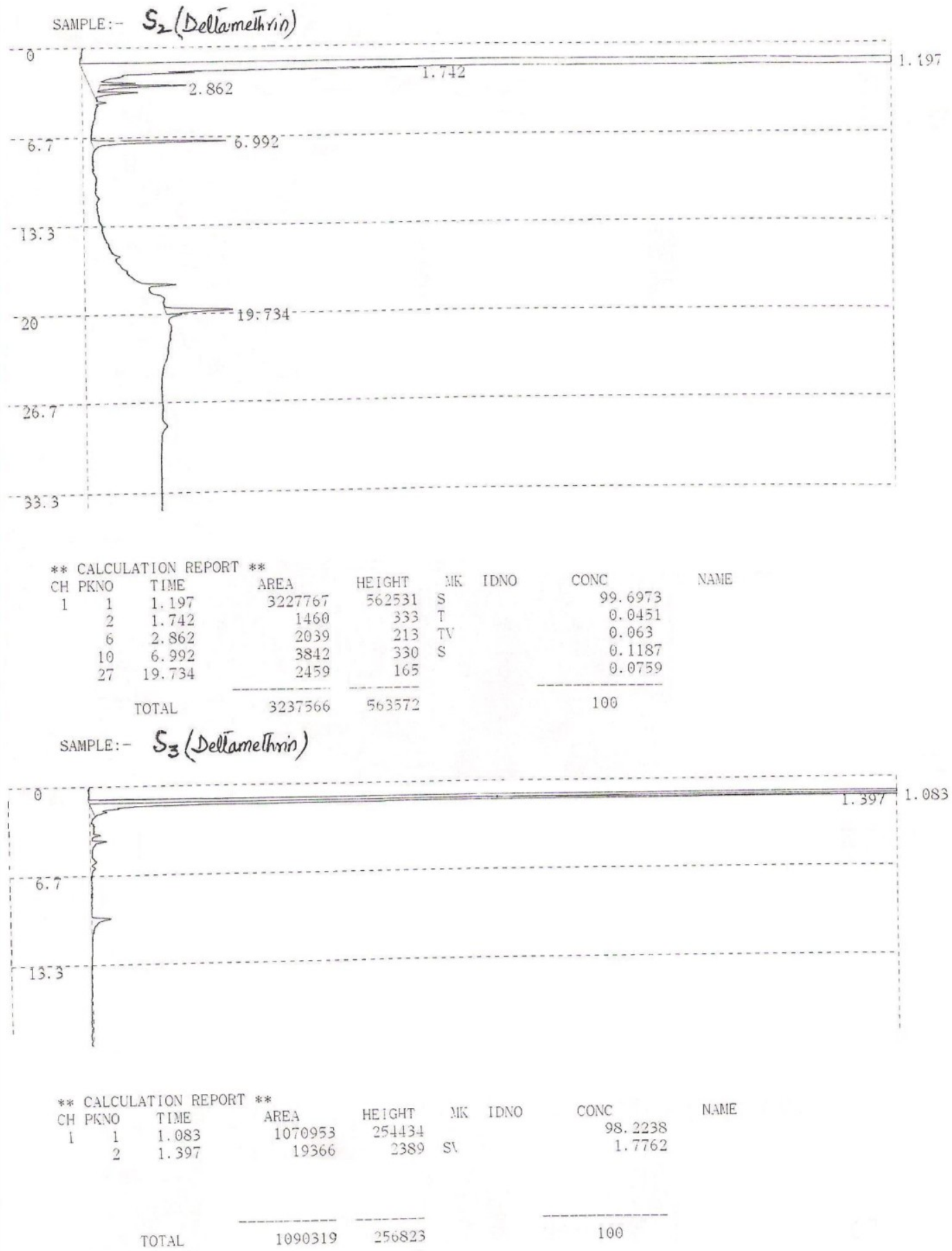

Figure 3. Scan of deltamethrin standard and sample

Experimentally analyzed concentration of deltamethrin in blood is more as compared to the urine. It proved that the intake rate of deltamethrin in the body is higher than the excretion rate. Deltamethrin is excreted from the body through urine, so traces of deltamethrin must be accumulated in the kidney. It may be an important reason of kidney failure. It is clear from above results that an objectionable concentration of pesticides is found in animal specimens, although they are dependent for food only on plants. Humane beings are dependent for food, both on animals and plants. Certainly, human beings are also getting a definite quantity of pesticides from their food sources. These absorbed pesticides are producing lot of harmful diseases and irregularities in life.

\section{Conclusion}

It was concluded from the analysis of above samples that absorbed quantity of deltamethrin found to be higher than the accepted MRL values as standard given by EPA. Such high concentration of deltamethrin can 
cause lot of harmful effects in human beings and animals like simple irritation of the skin and eyes, affecting the nervous system, mimicking hormones causing reproductive problems and in addition causing cancer. It is the need of hour that awareness is required to a common person to improve the yield of a crop, pesticides are necessary but within limits. In order to avoid this fatal risk to animals and humane beings, such type of pesticides should be synthesized and used within limits which are friendly to the environment.

\section{Acknowledgment}

I am thankful to Higher Education Commission of Pakistan for providing me financial support to complete this research project. Moreover, I am also highly thankful to PCSIR Laboratories, Lahore-Pakistan for facilitating me about sample analysis.

\section{References}

[1]. Robert L. Metcalf “Insect Control” in Ullmann's Encyclopedia of Industrial Chemistry” Wiley-VCH, Weinheim, 2002

[2]. Zaveri, Mihir (Thursday, February 4, 2010). The Daily Californian (The Daily Californian). Retrieved 9 June 2012.

[3]. Thomson, W. T. Agricultural Chemicals Book I: Insecticides. Thomson Publications, Fresno, CA. 1992.

[4]. Bradbury, S. P. and Coats, J. R. Toxicokinetics and toxicodynamics of pyrethroid insecticides in fish. Environ. Toxicol. Chem. 8: 373-380, 1989.2-21.

[5]. Haug, G. and H. Hoffman. Chemistry of Plant Protection 4: Synthetic Pyrethroid Insecticides: Structures and Properties. SpringerVerlag. Berlin, Heidelberg, New York. (eds). 1990

[6]. Miller GT, Sustaining the Earth, 6th edition. Thompson Learning, Inc. Pacific Grove, California. (2004), Chapter 9, Pages 211-216.

[7]. Bouwman, B. Sereda and H.M. Meinhardt, H.; B. Sereda and H.M. Meinhardt "Simultaneous presence of DDT and pyrethroid residues in human breast milk from a malaria endemic area in South Africa".Environmental Pollution 144 (3): (December 2006). 902-9176.

[8]. Roussel Uclaf. Residues in lettuce, Federal Republic of Germany. Report RR-80.15.01/AF submitted by Roussel Uclaf to FAO.

[9]. Mc LEOD HA., RITCEY WR. Manual on Analytical Methods for Pesticide Residues in Foods. Health Protection Branch. Health and Welfare Canada, Ottawa, Canada. eds. 1973.

[10]. Yan Ding, et al J. Chromatogr. B. 2004, 810, 221-227.

[11]. G.F.Pang, et al J. Chromatogr. A 667 (1994) 348.

[12]. A.R. Fernandez-Alba et al J. Chromatogr. A 686 (1994) 263.

[13]. Y. Nakamura et al J. AOAC Int. 76 (1993) 1348

[14]. G.F.Pang, et al J. AOAC Int. 78 (1995) 1481.

[15]. R.J. Maguire et al J. Agric. Food Chem.37 (1989) 1153.

[16]. Bissacot DZ et al. J Anal Toxicol. 1997 Sep; 21(5):397-402.

[17]. Pursuant to section 11L of the Food Act 1981, I, Annette King, Minister for Food Safety, issue the following amendment to the New Zealand (Maximum Residue Limits of Agricultural Compounds) Food Standards 2005 (No.2). 